\title{
BELAJAR SEJARAH KOLONIAL MELALUI PAMERAN KOLEKSI LUKISAN JADOEL
}

\author{
Lilie Suratminto
}

\begin{abstract}
Pictures or paintings of high-rank officials hanged in government or public offices are not only a recent phenomenon. Francois Valentijn (1724-1726) wrote in his book, Oud en Neuw Oost Indien, the common practice of hanging pictures or paintings of high-rank officials even in the eighteenth century in Indonesia when the East India Company (VOC) had its power over the land. The Fatahillah Historic Museum in Jakarta has kept all the pictures and paintings of the Dutch Indies officials from the time of the East India Company (VOC) to 1942. The curriculum vitae of those persona is a corpus for research on some aspects of the Indonesian colonial history.
\end{abstract}

\section{Keywords}

Paintings, the East India Company (VOC), the Dutch East Indies, curator, governor, pictures, period of the government, tenure period of the Dutch officers.

\section{PENDAHULUAN}

Suatu hal yang menggembirakan bagi kawula muda khususnya para pelajar dan peminat plesiran ke tempat-tempat jadoel 'jaman doeloe', bahwa Museum Sejarah Daerah Khusus Ibu Kota Jakarta yang terletak di Jl. Fatahillah no. 1 Jakarta Kota sejak tanggal 31 Oktober sampai dengan 30 November 2007 telah menggelar pameran lukisan para Gubernur-Jenderal masa VOC sampai dengan berakhirnya masa kolonial pada tahun 1942. Dengan kata lain dari masa jabatan Gubernur-Jenderal Pieter Both (16101613) sampai dengan Gubernur-Jenderal Alidius Warmoldus Lambertus Tjarda van Starkenborgh Stachouwer (1936-1942). Pameran ini dibagi dalam empat periode secara kronologis, yakni masa kekuasaan VOC yang ditandai dengan lambang VOC, masa kekuasaan Prancis dengan lambang bunga lely, masa kekuasaan Inggris dengan lambang singa duduk, dan masa kolonial Hindia-Belanda dengan lambang dua ekor singa yang saling berhadapan di bawah mahkota (tiara) dan di bawanhya tertulis semboyan Willem van Oranye Je mainteindrai 'Aku akan pertahankan'.

Koleksi lukisan jadoel ini dilengkapi dengan keterangan singkat dari setiap 
gubernur-jenderal, dimaksudkan agar para pengunjung dapat memahami riwayat hidup para petinggi negara ini secara singkat dan menyeluruh (parsial dan holistik). Para Gubernur Jenderal masa VOC 'Vereenigde Oost Indische Compagnie' (Serikat Badan Usaha Dagang Belanda di Asia) mengawali kariernya di Batavia. Mereka menduduki berbagai jabatan di Hoge Regering 'Pemerintah Tinggi' atau di Raad van Nederlands-Indie (Dewan Hindia-Belanda) dan berbagai jabatan lain dalam pemerintahan dari tingkat klerk (juru tulis), boekhouder (tenaga pembukuan), onderkoopman (saudagar junior), koopman (saudagar), opperkoopman (saudagar senior), tweede opperkoopman (saudagar senior kelas dua), dan terakhir eerste opperkoopman (saudagar senior kelas satu). Seorang opperkoopman dapat menduduki jabatan Anggota luar biasa Dewan Hindia (Ordinaris van Raad van Indië) atau anggota biasa dari Dewan Hindia-Belanda sebagai Lid van Raad van Indië dalam Hooge Regeering 'Pemerintahan Tinggi' dan dapat juga dipilih menjadi gubernur-jenderal.

Dewan Hindia Belanda kemudian mengajukan gubernur-jenderal terpilih kepada Dewan XVII (Heeren Zeventien) di Amsterdam. Jika usulan disetujui, Dewan XVII akan mengeluarkan besluit. Sambil menunggu besluit (surat pengangkatan) seorang gubernur terpilih dapat menjalankan tugasnya. Oleh karena perjalanan Batavia-Amsterdam lebih dari 10 bulan, datangnya besluit sering terlambat dan beberapa kali terjadi besluit-nya sampai di Batavia, yang bersangkutan sudah keburu meninggal dunia. Dalam sejarah VOC pernah terjadi bahwa pengangkatan Abraham Patras (1735-1737) sebagai Gubernur Jenderal tidak melalui proses yang lazim, melainkan melalui voting. Hal ini membuat Valckenier dan van Imhoff sangat berang, karena Patras tidak pernah menduduki jabatan sebagai Anggota Dewan Hindia-Belanda.

\section{MASA PEMERINTAHAN PARA GUBERNUR-JENDERAL}

Gubernur masa kolonial Hindia-Belanda (Nederlandsch-Indië) sebagian besar memulai kariernya di Belanda. Pada masa Republik para Gubernur jenderal ini diangkat oleh De Heeren XVII (Dewan XVII) yang kamar dagangnya berkedudukan di Amsterdam. Pada masa Kerajaan mereka diangkat oleh Raja atau Ratu Belanda, kemudian ia berangkat ke Hindia Timur (Indonesia). Sangat menarik untuk diteliti secara mendalam dari berbagai bidang studi bahwa dari 33 Gubernur Jenderal VOC 23 di antaranya meninggal di Batavia pada saat sedang menjalankan tugas, sedangkan dari 32 Gubernur Jenderal Hindia-Belanda hanya tiga orang yang meninggal di Indonesia, di Batavia, di Bogor dan di Surabaya. Masa jabatan Gubernur Jenderal Hindia-Belanda rata-rata selama empat tahun. Masa jabatan Gubernur Jenderal VOC yang paling lama adalah Maetsuycker, yakni selama 25 tahun (1653-1678), dan yang paling pendek hanya selama tujuh bulan adalah Gubernur Jenderal Jan Willem Jansens (20 Februari 1811 - 18 September 1811), karena ia harus menyerahkan pemerintahan kepada Thomas Stamford Raffles. J.P. Coen adalah satu-satunya Gubernur Jenderal yang dipilih dua kali dengan tenggang waktu (1618-1623; 1627-1629). 


\section{VOC DI ASIA}

Untuk membangun pusat kegiatan perdagangan Badan Usaha Dagang Belanda di Asia (VOC), Gubernur-Jenderal Pieter Both menyewa sebidang tanah dari bupati Jayakarta Pangeran Wijayakrama atau Jayawikarta yang terletak di sebelah timur muara sungai Ciliwung seluas 50 X 50 vadem (ukuran panjang masa itu, 1 vadem $=6$ kaki atau 66 jengkal atau kira-kira 1,69 meter). Menurut perjanjian tanah yang disewa hanya sebagaim gudang untuk menimbun barang-barang dagangan, oleh karena itu orang Belanda boleh mendirikan sebuah loji semi permanen di situ. Ternyata Belanda memperkuat loji itu dengan tembok batu dan meletakkan meriam yang diarahkan pada keempat penjuru, termasuk mengarah ke dalem atau keraton Wijayakrama, dengan alasan untuk melindungi barang dagangannya. Tentu saja Pangeran ini sangat kecewa dan marah sekali kepada orang Belanda. Oleh karena itu, ia minta bantuan Thomas Dale pimpinan armada dagang Inggris yang letaknya berseberangan dengan loji VOC untuk mengusir orang Belanda. Usaha ini tidak berhasil karena VOC yang dipimpin JP Coen dengan bantuan armada dari Banda Neira dapat mengenyahkan orang Inggris. Sultan Banten yang merasa wewenangnya dilampaui oleh Pangeran Wijayakrama yang telah dianggap lancang menyewakan tanah untuk orang asing sangat marah dan mengirimkan pasukan untuk menangkap Pangeran Wijayakrama. Kini pasukan Banten berhadapan dengan Belanda. Dalam peperangan tersebut Belanda berhasil merebut wilayah Jayakarta dan membumihanguskannya termasuk dalem keraton Pangeran Wijayakrama. Di tempat tersebut didirikanlah Kota yang oleh Dewan XVII ditetapkan dengan nama Batavia (1619).

VOC memperoleh hak oktroi dari Republik Belanda Serikat melalui parlemennya (de Staten Generaal) yang isinya antara lain memberikan kekuasaan VOC untuk merekrut tentara dan personil-personilnya, mencetak mata uang, mengadakan perang dan perjanjian dengan penguasa-penguasa setempat, serta menetapkan monopli dagang di seluruh wilayah VOC. Wilayah operasi VOC ditetapkan mulai dari Tanjung Harapan Baik (Kaap de Goede Hoop) di Afrika Selatan sampai ke Pulau Deshima (Hirado) Jepang dan di sebelah Timur Nusantara sampai Selat Magelan di Amerika Selatan. Misi lain yang diemban yaitu untuk menghancurkan Sepanyol dan Portugis di seberang lautan. Para gubernur-jenderal VOC diangkat dan diberhentikan oleh Dewan Tujuh Belas melalui besluit'surat keputusan pengangkatan seseorang untuk jabatan tertentu' (Jw: beslit atau beselit).

\section{GUBERNUR JENDERAL MASA VOC}

Periode pemerintahan pertama adalah masa awal berdiri sampai masa berakhirnya Serikat Badan Usaha Dagang Belanda di Asia (VOC). Selama kurun waktu hampir 200 tahun (1602-1799) telah terjadi silih-berganti gubernur-jenderal sebanyak 33 kali. Beberapa gubernur yang paling menonjol di antaranya J.P. Coen, Hendrik Brouwer, Rijckloff van Goens, Cornelis Speelman, Joan van Hoorn, Zwaardecroon, Adriaan Valckenier, Gustaaf 
Willem Baron van Imhoff.

J.P. Coen sangat terkenal sebagai pendiri kota Batavia. Ia yang mempertahankan pendapat bahwa armada dagang harus dilindungi oleh angkatan perang mengingat banyaknya perompakan di lautan. Dengan armada perang VOC dapat memaksakan sistem monopli dagang dengan penguasa-penguasa pribumi setempat untuk hanya menjual dagangan tertentu mereka terutama rempah-rempah pada VOC. JP Coen juga terkenal karena ia merupakan gubernur-jenderal VOC yang berhadapan langsung dengan pasukan Sultan Agung raja Mataram yang menyerang Batavia sebanyak dua kali $(1627 ; 1629)$. Ia juga terkenal sebagai seorang gubernur-jenderal yang bertangan besi (Heuken 2003, 15).

Hendrik Brouwer terkenal karena ia memperkenalkan rute baru yang memanfaatkan arah angin untuk mencapai Hindia-Belanda, dari tanjung Harapan melalui pantai Barat Australia dengan waktu tempuh enam bulan. Ini menghemat biaya dan waktu lima sampai enam bulan. Rute ini disebut rute Seynbrief atau Jalur Brouwer. Rijckloff van Goens terkenal dengan jurnal perjalanannya ke keraton Mataram dalam Javase Reyse. Pada waktu itu sudah ada perdamaian dengan kerajaan Mataram dan VOC boleh mengirimkan wakilnya di Mataram sebagai duta VOC. Rijckloff van Goens selama di dalam keraton Mataram mempelajari adat istiadat Jawa dan menggambarkan sumber potensial kerajaan Mataram bagi kepentingan VOC, misalnya berapa besar jumlah panen padi yang dihasilkan Mataram. Hal ini sangat penting untuk pemasokan logistik bagi Batavia yang penduduknya kian padat. Speelman terkenal karena dalam merintis kariernya di bawah Gubernur-Jenderal Maetsuyker ia berhasil menguasai Makassar, Ternate Tidore, dan Banten. Ia memerintah dengan masa jabatan sangat pendek karena ia meninggal saat masih menjabat (1681-1684). Upacara penghormatan terakhir pada saat pemakamannya merupakan upacara yang termegah dan termahal sepanjang sejarah VOC.

Willem van Outhoorn adalah satu-satunya Gubernur Jenderal VOC yang diizinkan menikmati masa pensiunnya di Hindia Belanda. Selama masa pensiunnya ia mengalami beberapa kali pergantian Gubernur Jenderal VOC. Ia bahkan yang merancang peti mati untuk pemakamannya kelak dan batu nisannya yang dipesan dari India serta mengatur bagaimana prosesi pemakamannya. Di samping itu ia merancang lencana-lencana emas dan perak yang akan dibagikan kepada para pengusung jenazahnya saat peti matinya diberangkatkan ke tempat pemakaman di Nieuwe Hollandsche Kerk 'Gereja Belanda Baru' yang sekarang berfungsi sebagai Museum Wayang. Willem van Outhoorn adalah mantan Gubernur Jenderal pertama yang mempergunakan kereta jenazah yang ditarik kuda sebagai pengangkut jenazah.

Joan van Hoorn menantu Willem van Outhoorn adalah pengganti Willem van Outhoorn terkenal karena namanya diabadikan sebagai peletak batu pertama pembangunan kembali gedung Stadhuis sebagai Gouverneurskantoor (1707) yang kini dikenal sebagai Gedung Museum Sejarah di jalan Fatahillah Jakarta Kota. Zwardecroon 
terkenal karena budidaya kopi Priangan yang sangat menguntungkan Kompeni. Hukuman yang sangat kejam terhadap Pieter Erbeveldt di Pecah Kulit membuat namanya sering disebut dalam sejarah VOC. Batu nisan Zwardecroon adalah batu nisan yang paling indah dari semua batu nisan pejabat VOC (Suratminto 2006).

Gubernur-Jenderal Gustaaf Willem Baron van Imhoff (1743-1750) sangat terkenal dalam usahanya memperbaiki kota Batavia yang hancur setelah peristiwa Pembantaian Etnis Cina diBatavia(1740). Semasa pemerintahannya ia mencetuskangagasan mendirikan bank pertama di Hindia Belanda De Bank van Leenig. Ini adalah cikal bakal Bank Indonesia. Selama masa pemerintahannya Van Imhoff terkenal sebagai pembaharu.

Hal-hal yang dilakukan Baron van Imhoff antara lain, dalam bidang pertanian di seputar Batavia (Ommelanden) dengan membuka perkebunan dan pertanian secara besar-besaran. Dalam bidang pendidikan ia membuka sekolah Latin, Seminari dan Akademi Marine (Academie de Marine). Dalam bidang korespondensi ia mendirikan Kantor Pos pertama di Batavia. Dalam bidang jurnalistik ia mengizinkan diterbitkannya koran Nouvelle. Dalam bidang arsitektur ia mendirikan Istana Bogor, Istana Cipanas sebagai tempat transit yang strategis karena istana tersebut terletak di antara Bogor (Buitenzorg) dan Toko Merah (rumah pribadi).

Di samping itu ia adalah gubernur-jenderal pertama yang mengunjungi kraton Mataram. Campur tangan Van Imhoff dalam masalah intern kerajaan itu justru membuat Mataram pecah menjadi Kesultanan dan Kasunanan (babad Gianti). Demikian juga campur tangan Van Imhoff di kesultanan Banten membuat Banten semakin lemah. Hal ini mungkin yang dikehendaki Kompeni agar kerajaan-kerajaan di seluruh Hinida-Belanda takluk kepada Kompeni.

Tidak semua gubernur-jenderal beretnis Belanda. Dalam masa VOC terdapat tiga orang gubernur-jenderal yang berasal dari Jerman, yaitu Rijckloff van Goens (167816810 yang lahir di Rees, Jerman 24 Juni 1649. Johannes Thedens (1741-1743) lahir di Frederichtstadt, Jerman 1680, dan Gustaaf Willem Baron van Imhoff (1743-1750) lahir di Rees, Frieslandia Timur, Jerman. Di samping itu ada juga yang berasal dari Prancis yaitu Gubernur-Jenderal Abraham Patras (1735-1737) yang lahir di Grenoble 22 Mei 1671.

Sudah disebutkan di awal makalah ini bahwa Gubernur-Jenderal Maetsuyker adalah gubernur yang paling lama menduduki jabatannya selama 25 tahun (1653-1678). Seratus tahun kemudian Gubernur-Jenderal Petrus Albertus van der Parra selama 14 tahun (1761-1775). Ia menduduki rangking kedua yang menjabat gubernur-jenderal paling lama. Pada umumnya masa jabatan gubernur-jenderal VOC adalah empat tahun, dan mereka pada umumnya berhenti menjabat karena meninggal dunia. Dari 23 gubernur-jenderal yang meninggal di Batavia, hingga saat ini hanya ada 7 buah nisan mereka yang dapat ditemukan (Suratminto 2006, 134-5). 


\section{GUBERNUR-JENDERAL MASA PRANCIS}

Periode kedua adalah masa pemerintahan Republik Bataf. Gema Revolusi Prancis pada tahun 1785 dengan semboyan persamaan hak, persaudaraan dan kebebasan membangkitkan semangat kaum patriot yang anti Oranye di Belanda. Kaum patriot dengan bantuan tentara Prancis pada tahun 1795 mendirikan Republik Bataf menggantikan Republik Belanda Serikat. Dalam coup d'etat yang dipimpin oleh Daendels (1798) Pangeran Willem I terpaksa mengungsi ke Inggris. Dengan bergantinya pemerintahan di Belanda VOC di Asia otomatis masuk kekuasaan Republik Bataf dan secara langsung ikut berhadapan dengan Inggris sebagai musuh Prancis. Blokade armada Inggris di Teluk Jakarta mengakibatkan putusnya hubungan VOC dengan negeri Belanda. Hal ini pula yang turut mempercepat proses runtuhnya VOC (1799). Seluruh wilayah VOC di luar Jawa satu per satu sdaha terlebih dahulu jatuh ke tangan Inggris. Wilayah Republik Bataf praktis hanya meliputi pulau Jawa saja. Selama pemerintahan Republik bataf, praktis kekuasaan pemerintahan hanya Jawa saja.

Tokoh yang paling terkenal pada masa Prancis adalah Gubernur Jenderal Herman Willem Daendels (1808-1811) yang adalah seorang mantan pemimpin coup d'etat di Belanda. Tugas Daendels pada masa kekuasaannya hanya meliputi Jawa saja oleh karenanya ia dapat lebih mengkonsentrasikan dan menggalang kekuatan di sini. Pada masa kekuasaan Daendels Jawa dibagi dalam karesidenan-karesidenan yang diberi label A untuk Banten, B untuk Batavia (Jakarta sekarang), C untuk Cirebon, D untuk Bandung, H untuk Semarang, K untuk karesidenan Jepara-rembang (Pati), dan lain-lain. Kode-kode huruf tersebut sampai sekarang dijadikan kode nomor pelat mobil.

Daendels yang hanya mahir dalam perang kontinental merasa tidak sanggup melawan Inggris di lautan. Untuk mencegah masuknya pasukan Inggris ke Batavia ia menghancurkan Kastil Batavia dan juga Gereja Belanda Baru (Nieuw Hollansche Kerk, sekarang Museum Wayang) karena dianggap sebagai simbol kebangsawanan yang dikhawatirkan akan jatuh ke tangan Inggris. Daendels memerintah dengan tangan besi. Oleh karena itu ia dijuluki Jenderal Guntur. Peninggalannya yang terkenal adalah jalan pos dari Anyer sampai Panarukan yang dalam pembangunannya menelan ribuan korban jiwa para pekerja paksa (rodi). Pada masa Daendels, bidang hukum mengalami perbaikan.

\section{GUBERNUR JENDERAL MASA INGGRIS}

Periode ketiga adalah masa pemerintahan Inggris. Setelah Inggris menghancurkan benteng Belanda di pulau Onrust di bawah H.L Ball dan E. Pellew, maka dengan mudah tentara mereka memasuki Batavia (1806). Gubernur-Jenderal Willem Janssens pengganti Daendels yang baru memerintah selama tujuh bulan dengan sangat mudah takluk kepada Inggris. Dalam masa pemerintahan Inggris tidak banyak perubahan. Sir Thomas Stamford Raffles banyak menaruh perhatian 
pada seni budaya khususnya seni budaya daerah Nusantara.

Masuknya Inggris ke Jawa banyak dibantu oleh Dr. John Casper Leyden. Dia seorang linguis yang poliglot (menguasai banyak bahasa). Dia juga mempengaruhi rajaraja Jawa yang pada saat itu sangat dendam terhadap Daendels karena tindakannya yang mereka anggap sewenang-wenang. Leyden meninggal sehari setelah kejatuhan Jatinegara ke tangan Inggris. Ia dimakamkan di pemakaman Kerkhoflaan (Tanah Abang I). Tak lama kemudian Marianne istri Raffles juga meninggal dan dimakamkan di samping Leyden. Untuk mengenang istri tercinta ini dibuatlah replika makamnya di Kebun Raya Bogor. Di samping sebagai kepala pemerintahan, Gubernur-Jenderal Raffles aktif menulis antara lain karyanya yang sangat terkenal adalah History of Java.

\section{GUBERNUR-JENDERAL MASA KOLONIAL HINDIA-BELANDA}

Periode keempat adalah masa kolonial Hindia-Belanda. Setelah kekalahan Prancis di Eropa dan diasingkannya Napoleon Bonaparte ke pulau St. Helena, timbullah perubahan politik di Eropa secara besar-besaran. Pangeran Willem I kembali ke Belanda dan diangkat menjadi raja kerajaan Nederlanden yang meliputi wilayah Belanda dan Belgia dan P. Jawa sebagai wilayah koloninya di seberang lautan. Pemerintahan yang terdiri atas wakil-wakil yang dipilih rakyat secara langsung dilaksanakan oleh kabinet yang dipimpin oleh seorang Perdana Menteri. Raja hanya sebagai simbol persatuan bangsa dan berperan dalam acara-acara seremonial misalnya dalam peresmian badanbadan pemerintahan, peresmian gedung, atau pembukaan sidang parlemen.

Dalam masa kolonial Hindia-Belanda ini pemerintah sudah mulai teratur dengan adanya hukum-hukum dengan sistem peradilannya. Pemerintah Hindia-Belanda mengalami beban yang paling berat yaitu konflik dengan Pangeran Diponegoro yang mengakibatkan Perang Diponegoro atau Perang Jawa (1825-1830) yang menewaskan kira-kira 15.000 tentara Belanda dan 200.000 pengikut Diponegoro. Akibat peperangan ini dan juga membuat pemerintah lemah dan Belgia memisahkan diri menjadi sebuah kerajaan yang meliputi Walonia yang berbahasa Prancis dan Flandria yang berbahasa Vlams atau Belanda (1830) dan akibat peperangan tersebut kas negara menjadi kosong.

\section{CULTUURSTELSEL YANG MEMAKMURKAN NEGERI BELANDA DAN MENYENGSARAKAN PENDUDUK PRIBUMI}

Kekosongan akibat kekurangan kas negara dari dalam pemerintahan tersebut membuat negeri Belanda mengalami krisis ekonomi. Pada saat itu Van den Bosch yang mantan Gubernur di Suriname mengajukan proposal kepada Raja Willem I untuk mengubah Jawa menjadi sebuah tambang emas hijau. Setelah Van den Bosch diangkat menjadi gubernur-jenderal di Hindia-Belanda, ia menerapkan Cultuur Stelsel yang maknanya adalah sistem budidaya tanaman. Rakyat diwajibkan untuk menanami seperlima dari tanah mereka dengan tanaman-tanaman yang diperlukan di pasaran 
dunia, misalnya kopi, karet, tebu, nila, teh. Dalam prakteknya Cultuur Stelsel adalah sistem tanam paksa. Banyak terjadi penindasan dan perlakuan sewenang-wenang oleh penguasa pribumi sendiri yang ingin lebih banyak keuntungan dari pemerintah. Dampak dari Cultuur Stelsel ini adalah mengalirnya keuntungan ke dalam kas Belanda dalam jumlah yang sangat besar. Sebaliknya di Jawa terutama di daerah Grobogan Jawa Tengah ribuan orang meninggal dunia karena kelaparan.

\section{POLITIK PINTUTERBUKA DAN POLTIK ETIS}

Kemakmuran kepulauan Nusantara membuat iri para pengusaha swasta dan asing yang juga ingin menjalankan usahanya di sini. Karena khawatir Hindia-Belanda akan jatuh ke tangan asing, pemerintah mengeluarkan Undang-Undang Agraria (1870) yang isinya antara lain penghapusan tanah-tanah pertikelir, sekaligus mengakhiri Cultur-stelsel. Pada masa pemerintahan Gubernur-Jenderal Otto van Rees (1884-1888) banyak perusahaan asing diizinkan membuka usahanya di Hindia-Belanda, misalnya perkebunan kelapa sawit, karet, dan tembakau di Sumatera dan Jawa. Kebijakan membuka kesempatan orang asing dan swasta untuk membuka usaha di Hindia-Belanda dikenal sebagai politik pintu terbuka (Open Deur Politiek).

Pada masa pelaksanaan Cultuurstelsel, tingkah laku bupati Lebak yang menurut Dauwes Dekker semena-mena terhadap rakyatnya dilaporkan kepada GubernurJenderal Albertus Jacobus Duijmaer van Twist (1851-1856). Laporan itu tidak mendapat tanggapan Van Twist. Karena sangat kecewa, sekembalinya ke negeri Belanda Dauwes Dekker menulis buku yang sangat mashur ke seluruh dunia, Max Havelaar. Buku ini telah menginspirasi R.A.Kartini dan nasionalis-nasionalis muda seperti Bapak Pendidikan Nasional Ki Hadjar Dewantara, Soekarno, dan Hatta.

\section{PERMASALAHAN GUBERNUR-JENDERAL MASA KOLONIAL HINDIA-BELANDA AWAL ABAD 20}

Pada paruh pertama abad ke-20 ini banyak masalah yang dihadapi oleh para gubernur-jenderal Hindia-Belanda. Masalahnya mulai dari penerapan politik etis, pemadaman perang Aceh (dari akhir abad 19 sampai tahun 1930) dengan mengatasnamakan ratu (In naam der Koningin) yang sangat menguras tenaga, biaya dan pikiran, serta ribuan korban jiwa. Masalah lain yang sangat penting adalah munculnya gerakan nasionalisme. Pemerintah mencoba mencegahnya dengan menerapkan undang-undang dan sangsi yang amat keras dengan alasan untuk menegakkan ketenteraman dan keteraturan (rust en orde). Pemerintah koolonial menganggap para penggerak organisasi nasionalis itu sebagai penyebar kebencian dan oleh karenanya keluarlah pasal-pasal yang disebut haatzaai artikelen yang sangat dibenci rakyat. Terjadi penangkapan-penangkapan para pemimpin pergerakan nasional dan pembuangan terhadap sejumlah tokoh gerakan kemerdekaan ke penjara Sukamiskin di Bandung, Endeh, Bengkulu dan Boven Digoel di Irian. 
Pada masa pemerintahan Gubernur-Jenderal Andries Cornelis Dirk de Graeff (1926-1931) gerakan nasionalis mulai menghembuskan perbedaan sini-sana (hier 'orang pribumi' dan daar 'orang Belanda'). Pada masa itu pegawai pemerintahan (Binnenlands Bestuur) dikenal sangat galak dan ditakuti banyak orang. Bonifacius Cornelis de Jonge (1931-1936) tidak kurang kerasnya. Ia bahkan melaksanakan hal yang sangat dibenci orang banyak, bahkan oleh bangsa Belanda sendiri, yaitu pembredelan terhadap sejumlah media cetak yang mendukung pergerakan nasional. Dengan congkaknya ia sesumbar: "Kita (bangsa Belanda) sudah berada di Hindia-Belanda selama 300 tahun, kita pasti harus bisa berada di sini 300 tahun lagi". Kata-kata itu justru dipakai Bung Karno untuk semakin membakar semangat rakyat untuk membenci pemerintah kolonial dan menuntut kemerdekaan.

\section{MASA KEMENANGAN PARTAI POLITIK}

Sesumbar Gubernur-Jenderal Cornelis de Jonge itu ternyata tidak terbukti. HindiaBelanda tamat riwayatnya pada masa pemerintahan penggantinya yaitu GubernurJenderal Alidius Warmoldus Lambertus Tjarda van Starkenborgh Stachouwer (19361942). Pendudukan Jepang selama tiga setengah tahun membuyarkan impian Cornelis de Jonge. Sejak kedatangan Jepang nama Batavia diubah menjadi Jakarta. Bung Karno dan Bung Hatta atas desakan para pemuda pada tanggal 17 Agustus 1945 didaulat untuk membacakan naskah Proklamasi Kemerdekaan bangsa Indonesia. Sejak saat itu tidak ada lagi gubernur-jenderal yang memerintah Indonesia, dan sebagai gantinya adalah presiden Republik Indonesia.

\section{KESIMPULAN}

Beruntung sekali bahwa Museum Sejarah Jakarta mempunyai koleksi lukisan para gubernur-jenderal yang lengkap dari masa ke masa tersebut. Sebelumnya koleksi ini sempat terbengkalai karena kurangnya dana pemeliharaan. Pameran lukisan para gubernur-jenderal disertai informasi lengkap tentang mereka secara kronologis memberikan wawasan sejarah kolonial secara holistik (menyeluruh), dengan harapan agar generasi muda dapat menarik pelajaran dalam mencapai cita-cita mereka untuk menjadikan bangsa Indonesia menjadi bangsa yang besar di antara bangsa-bangsa lain di seluruh dunia.

Runtuhnya VOC karena para pejabatnya korupsi dan keruntuhan Hindia-Belanda karena Perang Dunia II dan semangat nasionalisme yang tinggi dari bangsa Indonesia. Bagaimana dengan situasi Indonesia pascareformasi? Jika korupsi meningkat dan nasionalisme semakin tipis, bahaya kehancuran bangsa mengancam kita semua. Marilah kita belajar dari pengalaman para gubernur jenderal kedua periode ini. 


\section{DAFTAR PUSTAKA}

Ataladjar, Thomas B. Toko Merah Saksi Kejayaan Batavia Lama di Tepian Muara Ciliwung: Riwayat dan Kisah para Penghuninya. Kata Pengantar A. Lapian. Jakarta: Dinas Kebudayaan dan Permuseuman DKI Jakarta. 2003.

Fasseur, Cees. Indischgasten. Amsterdam: Bert Bakker. 1997.

Heuken, Adolf. Gereja-gereja Tua di Jakarta; seri Gedung-gedung ibadaty tua di Jakarta. Jakarta: Cipta Loka Caraka. 2003.

Kloot, M.A. Rhede van der. Gouverneurs-Generaal en Commissarissen-Generaal van Nederlandsch-Indië 1610-1888. 's Gravenhage: W.F. van Stokkum. 1891.

Suratminto, Lilie. "Pembantaian Etnis Cina di Batavia 1740. Dampak Konflik Golongan Prinsgezinden dan Staatsgezinden di Belanda?" dalam Wacana: Jurnal Ilmu Pengetahuan Budaya. Depok: FIB UI, Vol. 6 No. 1, 1-26. 2004.

"Komunitas Kristen di Batavia masa VOC dilihat dari batu Nisannya, Suatu Kajian Semiotik dan Analisis Teks". Disertrasi. Depok: Fakultas Ilmu Pengetahuan Budaya Universitas Indonesia. Belum diterbitkan. 2006.

"Teks pada Batu Nisan Baron van Imhoff Dilihat melalui Analisis Semiosis Model Peirce dan Danesi-Perron" dalam Makara sei Sosial Humaniora. Depok: DRPM UI, ISSN 1693-6701, 1-12. 2007.

Vermeulen, Johannes Theodorus. "De Chinezen te Batavia ende Troebelen van 1740". 
Leiden: N.V. Boek en Steendrukkerij. Disertasi. 1938.

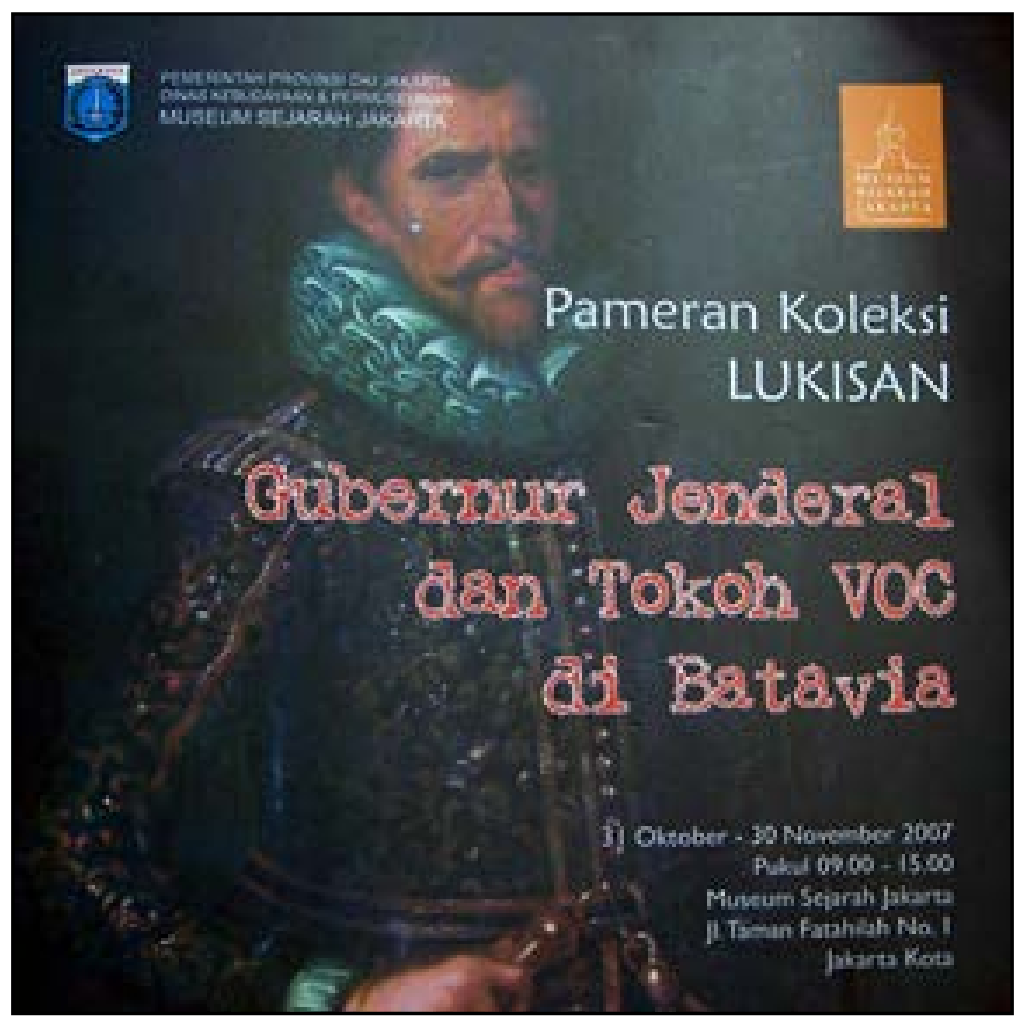

Foto 1. Buku panduan pameran lukisan Gubernur Jenderal masa VOC dan masa kolonial Hindia-Belanda. Foto: Lilie Suratminto.

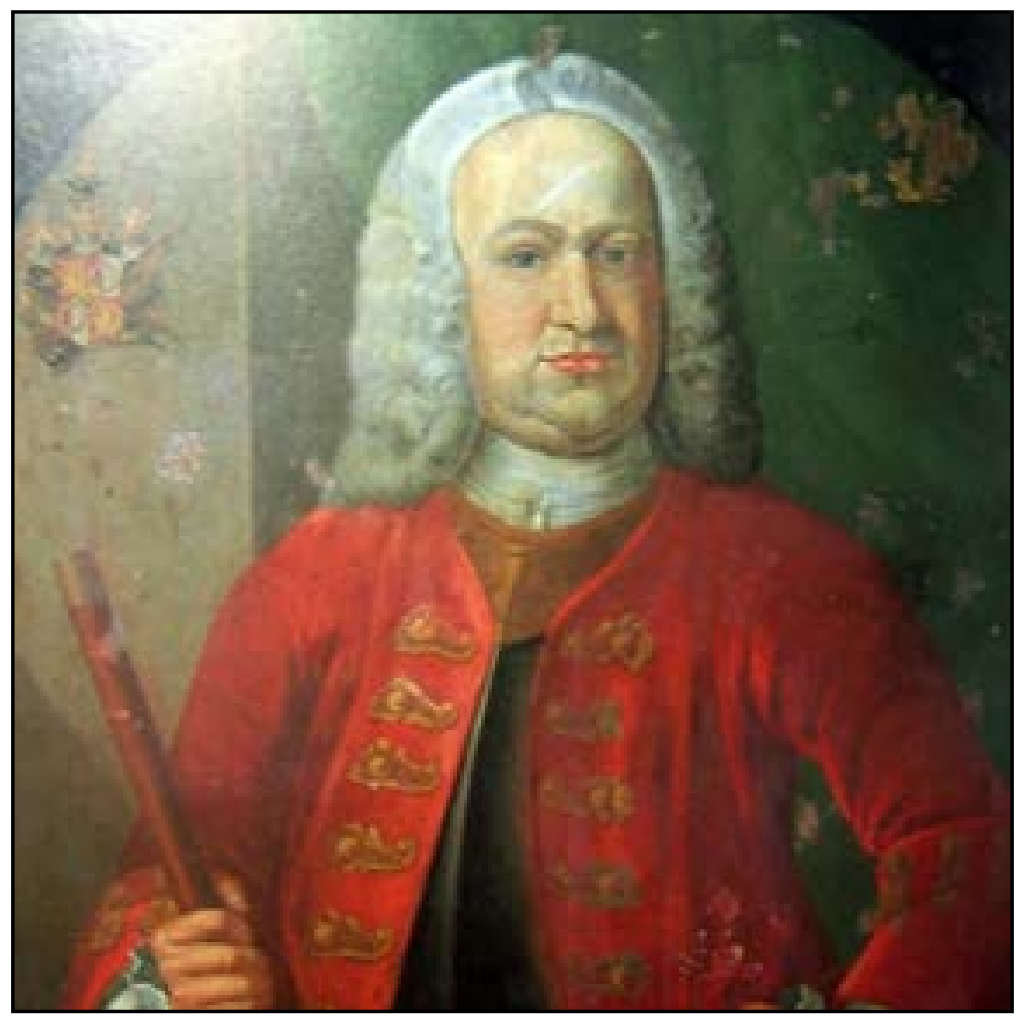

Foto 2. Gubernur-Jenderal Gustaff Willem Baron van Imhoff (1743-1750) pemilik gedung Toko Merah di Jakarta Kota membangun kembali kota Batavia yang hancur karena Huru-hara Cina 1740, ia antara lain mendirikan istana Bogor, sekolah Latin dan sekolah maritim.

Foto: Lilie Suratminto. 